\title{
SEARCHING FOR SCHIZOPHRENIA'S ROOTS
}

Sixty years after the first schizophrenia drug hit the market, researchers are still struggling to understand and treat the disorder. By Emily Elert.

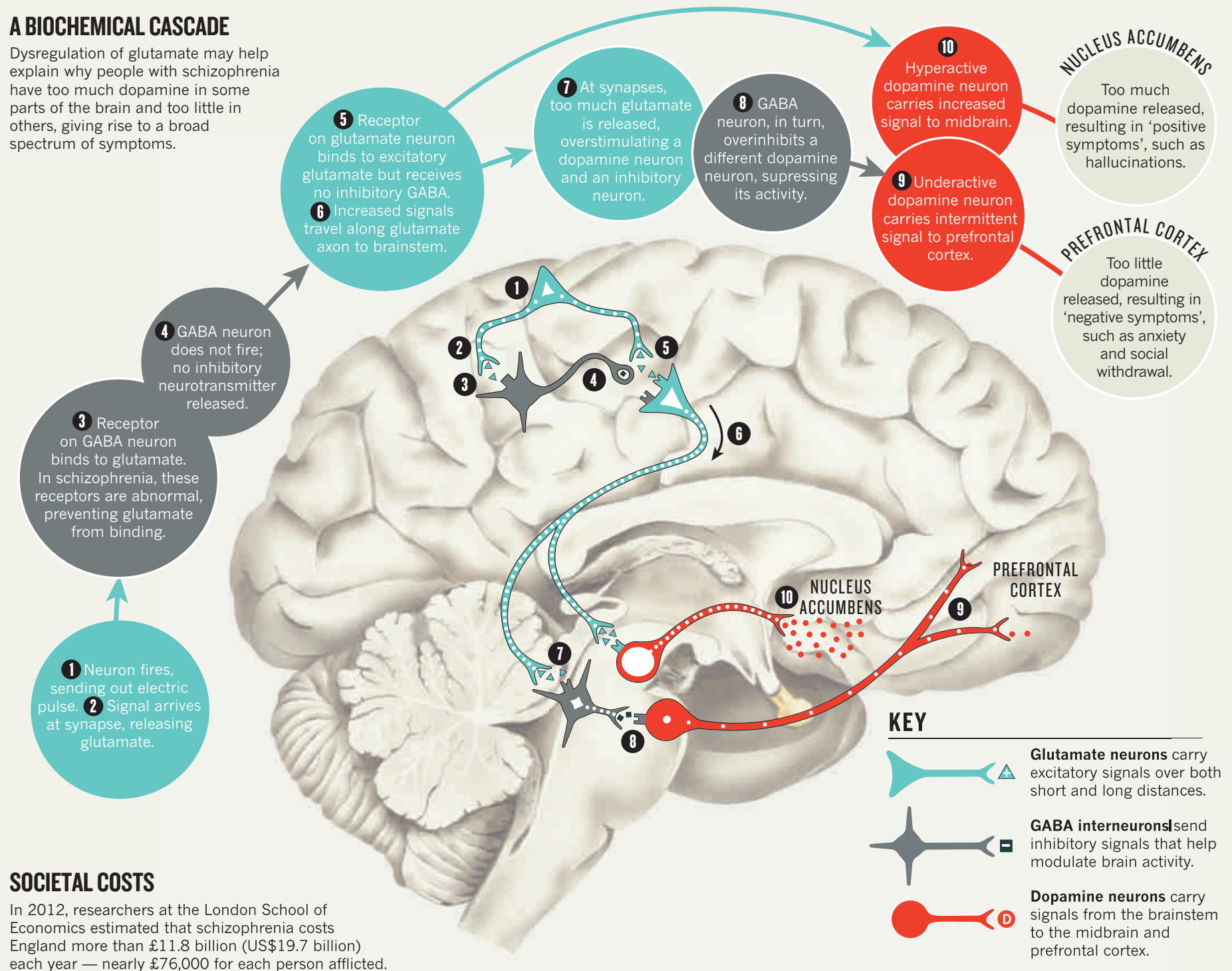

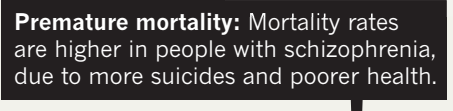

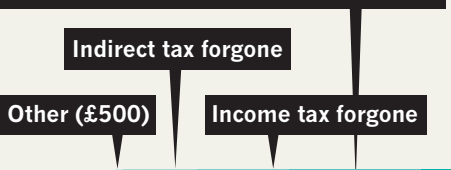

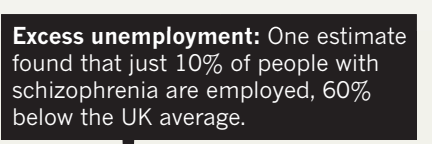

below the UK average.
Institutional: Most people with schizophrenia have at least one in-patient stay and a high risk of readmission.

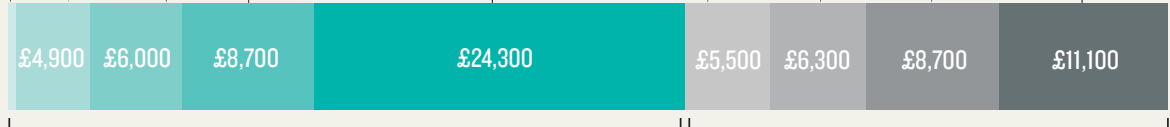




\section{THE CHANGING FACE OF SCHIZOPHRENIA}

The symptoms of schizophrenia vary from person to person, but follow a characteristic pattern over the course of the disease.

\section{POSITIVE SYMPTOMS}

The onset of schizophrenia is manifested by symptoms associated with psychosis. These often respond well to antipsychotic drugs.

\section{NEGATIVE} SYMPTOMS

These traits often linger or worsen, accompanied by impairments to cognitive processes, such as working memory.
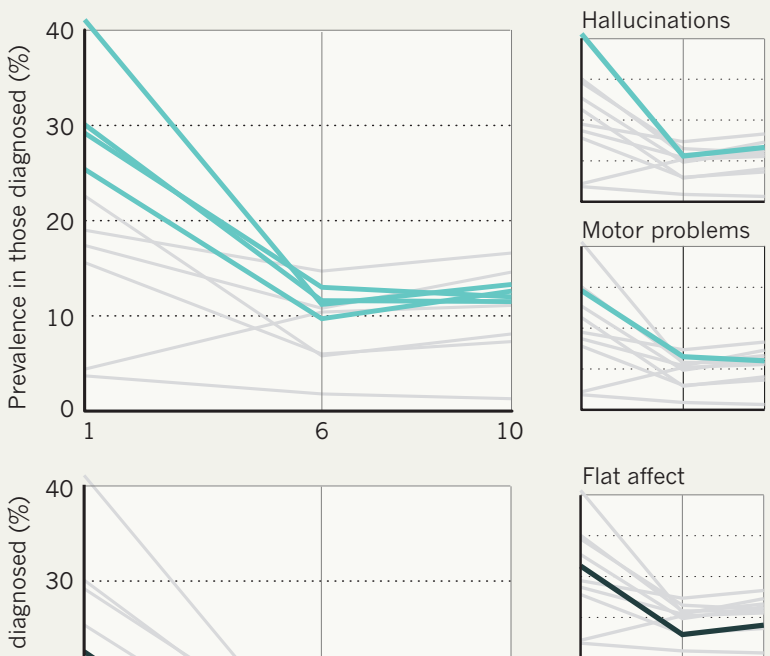

Apathy

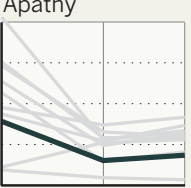

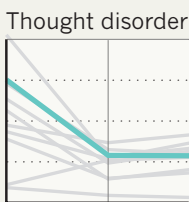

Delusions

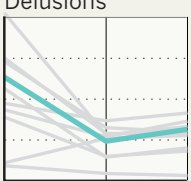

Odd behaviour

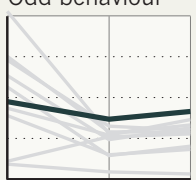

Self-neglect

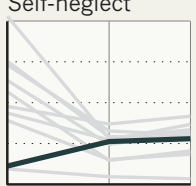

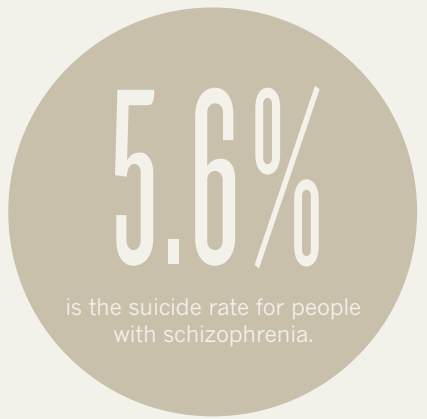

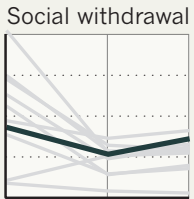

Anxiety

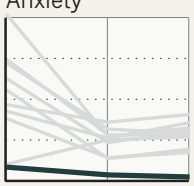

\section{YEARS OF DRUG DEVELOPMENT}

The most widely used schizophrenia drugs, atypical antipsychotics, are effective in treating positive symptoms. But researchers are finding new neural targets

to address negative and cognitive symptoms.

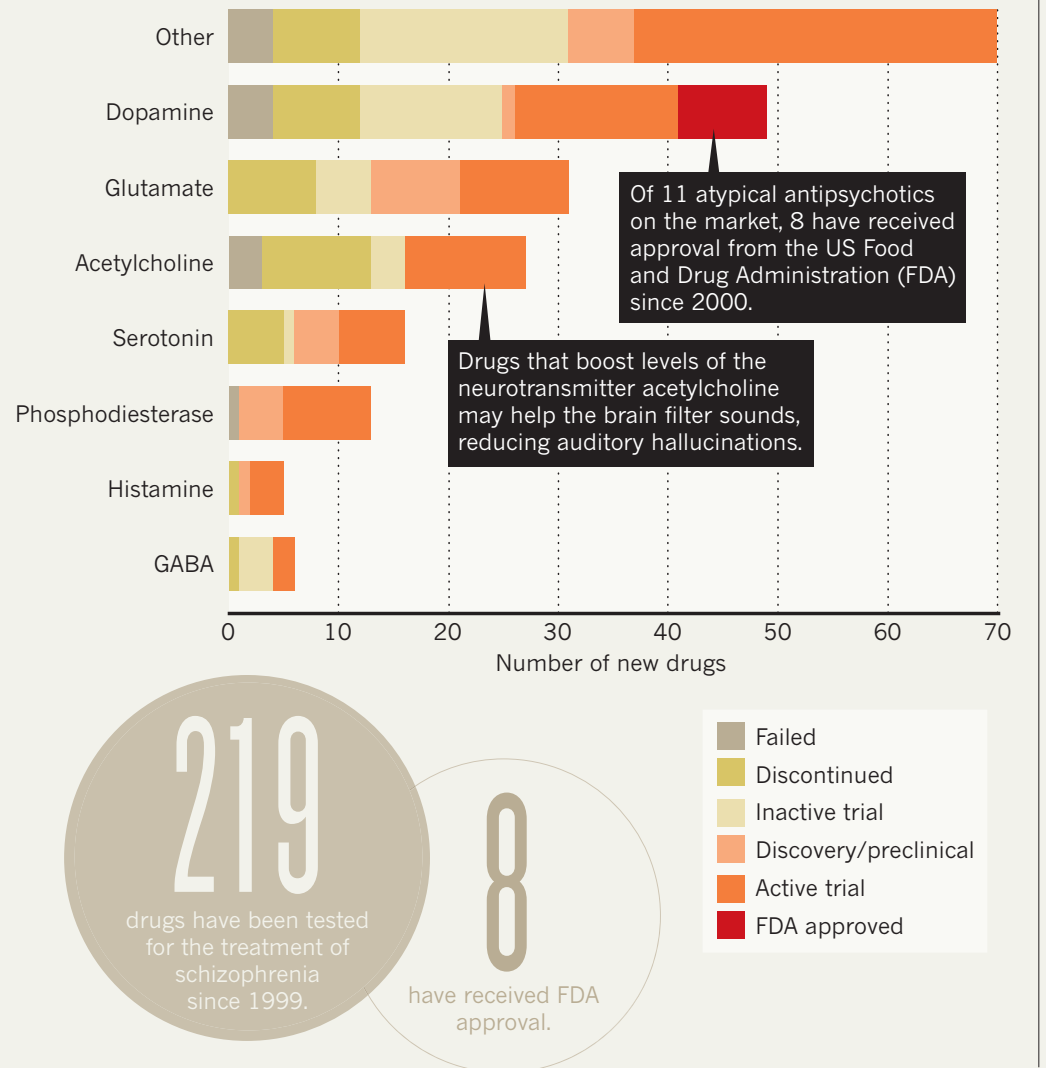

\section{SCHIZOPHRENIA SLOWDOWN}

For the past ten years, clinical trials of schizophrenia treatments have been on a downward trajectory, even though clinical trials in general have been rising.

Schizophrenia treatment trials
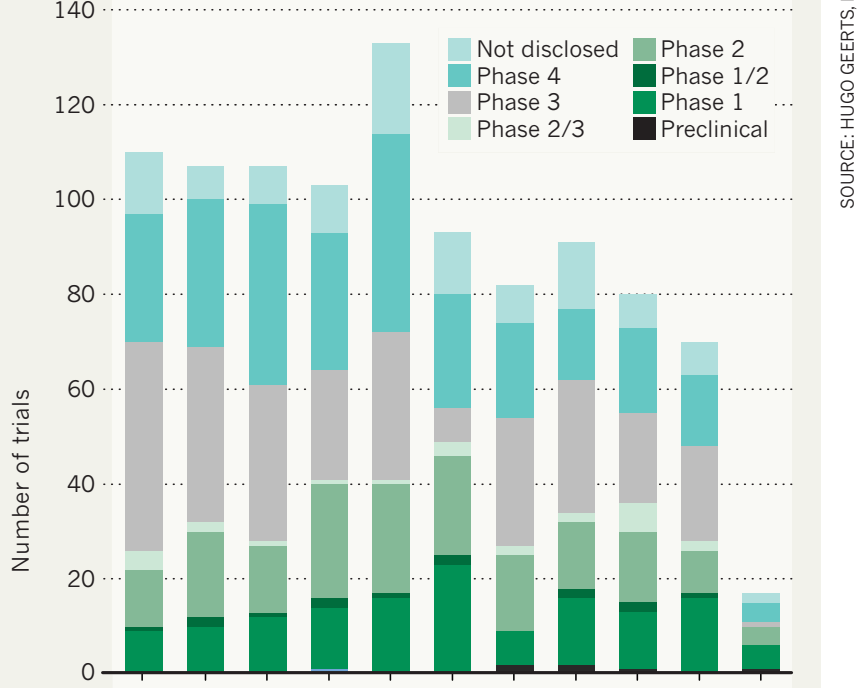
20,000

\section{All clinical trials}

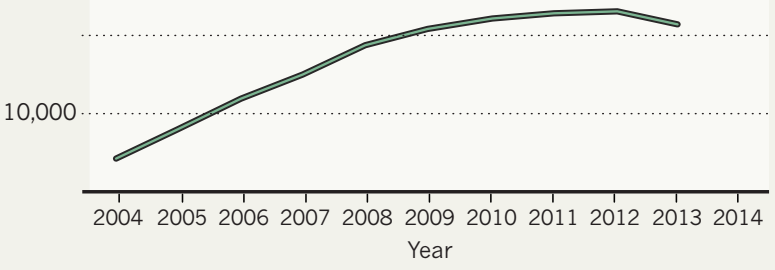

